\title{
Mechanics of the Respiratory System during Passive Exhalation in Preterm Lambs
}

\author{
PETER RICHARDSON, SCOTT JARRIEL, AND THOMAS N. HANSEN \\ Baylor College of Medicine, Department of Pediatrics, Division of Neonatology, Houston, Texas 77030
}

\begin{abstract}
Previous studies have shown large inhomogeneities in the distributions of ventilation and perfusion of newborn infants with hyaline membrane disease. The purpose of this study was to show that measurements of lung mechanics also show evidence of lung inhomogeneities and that a multiple compartment analysis of mechanics gives a more accurate representation of passive exhalation flow and volume than single valued mechanics. We studied 10 sedated preterm lambs (130 d gestation) weighing 2.2 $\pm 0.3 \mathrm{~kg}$ at $4 \mathrm{~h}$ postnatal age. Passive exhalation lung mechanics of the respiratory system were measured by obstructing gas flow near end inhalation then, after pressures within the lung reached equilibrium, allowing the animals to exhale to the atmosphere. Airway pressure and flow signals were monitored by a computer then analyzed using single and multiple compartment analyses. Single compartment analysis of time constant $(\tau)$ in $\mathrm{s}$, respiratory system resistance $(R)$ in $\mathrm{cm} \mathrm{H}_{2} \mathrm{O} / \mathrm{L} / \mathrm{s}$ and quasistatic compliance $(\mathrm{C})$ in $\mathrm{mL} / \mathrm{cm} \mathrm{H}_{2} \mathrm{O}$ yielded $\tau=0.16 \pm 0.07, \mathrm{R}=$ $92 \pm 17$, and $C=1.8 \pm 1.1$ (mean \pm SD). Multiple compartment analysis yielded "fast compartment" $\tau_{1}=$ $0.10 \pm 0.04, R_{1}=90 \pm 28$, and $C_{1}=1.1 \pm 0.5$ and "slow compartment" $\tau_{2}=0.25 \pm 0.12, R_{2}=503 \pm 288$, and $C_{2}$ $=0.7 \pm 0.6$. All of the animals studied exhibited nonlinearity in their flow-volume plots. Calculated flow-volume plots were much more accurately portrayed by the twocompartment analysis than by single valued mechanics. Multiple compartment analysis of lung mechanics may provide useful insight into the pathophysiology of the preterm lab with hyaline membrane disease. (Pediatr Res 26: 425-428, 1989)
\end{abstract}

\section{Abbreviations}

$\mathrm{C}$, quasistatic compliance of the respiratory system

$f V_{T}$, fraction of tidal volume ventilating each lung compartment

HMD, hyaline membrane disease

$R$, respiratory system resistance

$\tau$, passive exhalation time constant

$V$, volume of gas in the lungs above functional residual capacity

subscript 1 and 2 refer to the "fast" and "slow" compartments, respectively.

PIP, peak inspiratory pressure

PEEP, positive end expiratory pressure

Received January 13, 1989; accepted June 9, 1989.

Correspondence Peter Richardson, Ph.D., Department of Pediatrics, Baylor College of Medicine, One Baylor Plaza, Houston, TX 77030.

Supported by a research Grant 6-525 from the March of Dimes Birth Defects Foundation.
Several studies on infants with HMD suggest that gross inhomogeneities exist in their distributions of ventilation and perfusion. The elevations of nitrogen $(1,2)$, oxygen $(1-3)$, and carbon dioxide $(4,5)$ gradients between alveolar gas and arterial blood suggest that ventilation-perfusion mismatching exists and that there are respiratory units with both lower and higher than normal ventilation-perfusion ratios. Additional studies using nitrogen washout suggest that these infants also have an uneven distribution of ventilation (6). Multiple compartment analyses of the results from these studies provide valuable information that influences the interpretations of the pulmonary pathophysiology of infants with HMD.

After considering the strong evidence of lung inhomogeneities in infants with HMD, we speculated that lung mechanics measurements would also require multiple compartment analysis for accurate representation of flow and volume during ventilation. To investigate this hypothesis, we conducted studies on preterm lambs, which is an established animal model of HMD (7). As a basis for discussion, we applied both single- and double-compartment analyses to the passive exhalation flow-volume curves. The single compartment analysis gave conventional single valued constants for $\mathrm{C}, \mathrm{R}$, and $\tau$. The double compartment analysis provided two sets of lung mechanics constants and the volume of gas exiting from each compartmment during exhalation.

\section{MATERIALS AND METHODS}

Theory. Single compartment analysis. The analysis of flowvolume curves to obtain $\tau, \mathrm{R}$, and $\mathrm{C}$ is based on the application of the equation of motion as a force balance during passive exhalation:

$$
\mathrm{P}(\mathrm{t})=1 / \mathrm{C}^{*} \mathrm{~V}(\mathrm{t})+\mathrm{R}^{*} \mathrm{dV}(\mathrm{t}) / \mathrm{dt}+\mathrm{I}^{*} \mathrm{~d}^{2} \mathrm{~V}(\mathrm{t}) / \mathrm{dt}^{2}
$$

where: $P$ is the pressure across the respiratory system, $I$ is the inertance and $\mathrm{V}, \mathrm{dV} / \mathrm{dt}$, and $\mathrm{d}^{2} \mathrm{~V} / \mathrm{dt}^{2}$ are exhaled gas volume, gas flow, and gas acceleration; all are functions of time $(t)$. The contribution of inertial forces is relatively small and can be neglected (8). Therefore, equation 1 can be closely approximated by:

$$
\mathrm{dV}(\mathrm{t}) / \mathrm{dt}=-1 / \mathrm{RC} \mathrm{C}^{*}(\mathrm{t})+\mathrm{P}(\mathrm{t}) / \mathrm{R}
$$

During passive exhalation to atmosphere, the pressure across the respiratory system is zero and equation 2 becomes:

$$
\mathrm{dV}(\mathrm{t}) / \mathrm{dt}=-1 / \mathrm{RC}^{*} \mathrm{~V}(\mathrm{t})
$$

with the condition that at zero time:

$$
\mathrm{dV}(0) / \mathrm{dt}=\mathrm{P}(0) / \mathrm{R}
$$

Equation 3 is linear. The plot of $d V(t) / d t$ versus $V(t)$ has a slope of $-1 / \mathrm{RC}$ and an intercept of $\mathrm{P}(0) / \mathrm{R}$. Thus, the slope of the plot can be used to estimate $\tau$ (the product $\mathrm{RC}$ ) and the intercept can be used to estimate $R(9,10)$. The quasistatic compliance of the respiratory system can be estimated independently by dividing 


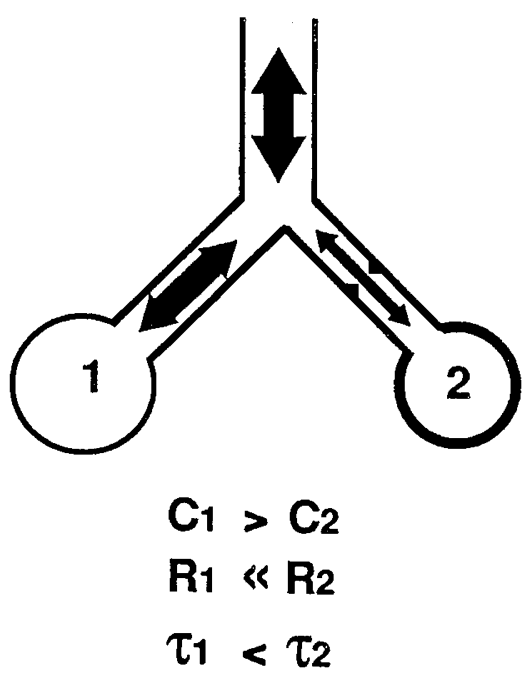

Fig. 1. Idealized lung made up of two compartments having different compliances, resistances and time constants.

the tidal volume by the pressure across the respiratory system at the start of exhalation.

Two compartment analysis. Figure 1 is an idealized representation of a lung consisting of two compartments. In this example, $C_{1}$ is greater than $C_{2}$ but $R_{1}$ is much less than $R_{2}$ causing $\tau_{1}$ to be less than $\tau_{2}$

To obtain useful equations for calculating $\mathrm{C}_{1}, \mathrm{C}_{2}, \mathrm{R}_{1}, \mathrm{R}_{2}, \tau_{1}$, and $\tau_{2}$, we start by rearranging equation $3 \mathrm{a}$ to:

$$
1 / \mathrm{V}(\mathrm{t}) * \mathrm{dV}(\mathrm{t})=-1 / \mathrm{RC}^{*} \mathrm{dt}
$$

and integrate from the start of exhalation to some time, $t$, during exhalation yields:

$$
\mathrm{V}(\mathrm{t})=\mathrm{V}(0)^{*} \exp (-\mathrm{t} / \mathrm{RC})
$$

where: $\mathrm{V}(0)$ is the volume above functional residual capacity at the start of exhalation when $\mathrm{t}=0$, and $\mathrm{RC}$ is the product of resistance and compliance. This product equals the time constant of the exponential expression.

Application of the model of two RC units in parallel (9) by using equation 3 for each compartments yields:

$$
\begin{aligned}
& \mathrm{V}_{1}(\mathrm{t})=\mathrm{V}_{1}(0)^{*} \exp \left(-\mathrm{t} / \mathrm{R}_{1} \mathrm{C}_{1}\right) \\
& \mathrm{V}_{2}(\mathrm{t})=\mathrm{V}_{2}(0)^{*} \exp \left(-\mathrm{t} / \mathrm{R}_{2} \mathrm{C}_{2}\right)
\end{aligned}
$$

The total volume exhaled $(\mathrm{V}(\mathrm{t}))$ is the sum of the volume exhaled from each compartment, $V_{1}(t)$ and $V_{2}(t)$, which yields the working equation:

$$
V(t)=V_{1}(0)^{*} \exp \left(-t / R_{1} C_{1}\right)+V_{2}(0) * \exp \left(-t / R_{2} C_{2}\right)
$$

In our two-compartment analysis, the constants of equation 5 were obtained by using curve fitting analysis of the log volume versus time plots. The slope of the lines obtained from linear regressions during the curve fitting were used to calculate the time constant $\left(\tau_{\mathrm{i}}\right)$ of each compartment and the intercepts were used to calculate the volume $\left(\mathrm{V}_{\mathrm{i}}(0)\right)$ exhaled from each compartment. Curve analysis was started at peak flow during passive exhalation; the portion of the curve (see Fig. 2) where flow is increasing was neglected in the calculations. The quasistatic compliance of each compartment $\left(\mathrm{C}_{\mathrm{i}}\right)$ was estimated by dividing the volume exhaled from each compartment by the pressure difference measured across the respiratory system just before the start of passive exhalation. The resistances $\left(R_{i}\right)$ were obtained by dividing the $\tau_{\mathrm{i}}$ by $\mathrm{C}_{\mathrm{i}}$.

Animal preparation. We studied 10 premature lambs of $130 \mathrm{~d}$ gestation (147-150 term) that weighed $2.2 \pm 0.3 \mathrm{~kg}$. Five ewes, each bearing twins, were sedated with ketamine (200-300 mg) then spinal anesthesia was induced by injecting 4 to $6 \mathrm{mg}$ of

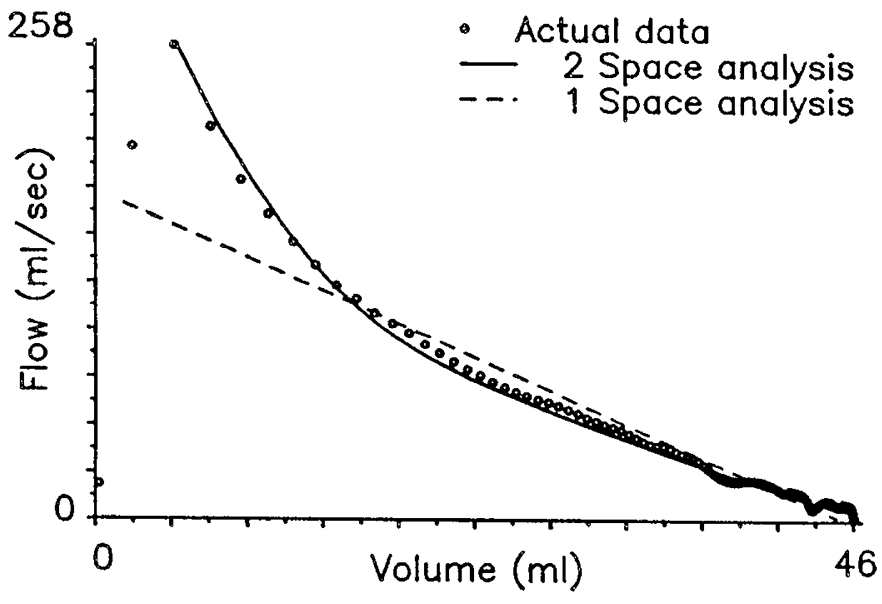

Fig. 2. Flow-volume curve during passive exhalation of premature lamb. The circled values are the actual data obtained at 10 -ms intervals.

tetracaine chloride diluted to a volume of 3 to $4 \mathrm{~mL}$ with $10 \%$ dextrose in water. Ketamine was given throughout the procedure as required for sedation. The ewes were placed supine on the operating table and their uteruses were exposed through a midline incision. The fetal hind limbs were located and exteriorized through a 2- to $3-\mathrm{cm}$ uterine incision. Cut downs on the lambs were performed under local anesthesia (1\% lidocaine) and catheters placed in the limb artery and vein. Pentobarbital was then administered intravenously.

The fetuses were delivered and, before clamping the umbilical cord, they were intubated with $4.0 \mathrm{~mm}$ ID cuffed endotracheal tubes. The airways were suctioned and the lungs expanded with $35 \mathrm{~cm} \mathrm{H}_{2} \mathrm{O}$ for $5 \mathrm{~s}$ and then lowered to $5 \mathrm{~cm} \mathrm{H}_{2} \mathrm{O}$ for $5 \mathrm{~s}$ (11). This lung expansion procedure was repeated three times and then the umbilical cord was clamped and cut. The lambs were dried with towels and then placed under an infant warmer on a heating pad that was adjusted to bring the rectal temperature to $39^{\circ} \mathrm{C}$. Heart rate and blood pressure were monitored and additional pentobarbital was administered as needed.

The lambs were mechanically ventilated with initial settings of $35 \mathrm{~cm} \mathrm{H} \mathrm{H}_{2} \mathrm{O}$ PIP, $5 \mathrm{~cm} \mathrm{H} \mathrm{H}_{2} \mathrm{O}$ PEEP, an inspiratory time of 0.2 $\mathrm{s}$ and a rate of 60 breaths $/ \mathrm{min}$. The initial oxygen concentration was $100 \%$. After $1 \mathrm{~h}$ of time for stabilization, PEEP was adjusted to maintain functional residual capacity in a normal range (12), then PIP and the fraction of $\mathrm{FIO}_{2}$ levels were adjusted in attempts to maintain $\mathrm{PaCO}_{2}$ and $\mathrm{PaO}_{2}$ within the ranges of 35-45 and $60-80 \mathrm{~mm} \mathrm{Hg}$. The $\mathrm{FIO}_{2}$ was never decreased by more than 0.1 between blood-gas evaluations.

Measurement system. Mechanics instrumentation consisted of a Fleisch "00" pneumotachometer (OEM Medical, Inc., Richmond, VA) placed between the ventilator tubing " $T$ " and the endotracheal tube. To obtain a position for obstructing exhalation flow between the pneumotachometer and the lamb (10) and also to be able to measure the lamb's airway pressure, we fabricated a "clamp connector" from a 3 -cm length of $3 / 8$-inch ID polyvinyl chloride tubing connected to a fitting that was machined to house the large end of an endotracheal tube adapter (similar to a standard ventilator tubing "T" piece). Endotracheal tube adapters that have "luhr-lock" side ports for sampling airway pressure (Respiratory Support Products, Inc., Costa Mesa, CA) were placed in the clamp connector and connected to the endotracheal tube. The other end of the clamp connector was attached to the pneumotachometer. Forceps were used to pinch the tubing and obstruct exhalation.

Blood pressure monitoring tubing was used to connect the pressure transducers to the pneumotachometer and endotracheal tube adapter. Variable reluctance pressure transducer-carrier demodulator systems, MP45-871, CD257 (Validyne, Inc., Northridge, $\mathrm{CA})$ were used with the pneumotachometer $\left( \pm 2 \mathrm{~cm} \mathrm{H}_{2} \mathrm{O}\right)$ 
and for airway pressure $\left( \pm 50 \mathrm{~cm} \mathrm{H}_{2} \mathrm{O}\right)$ monitoring. Pressure signals were conditioned by a $50 \mathrm{~Hz}$ low-pass filter (Validyne) then they were sampled by a 12-bit resolution analog to digital converter (model 570, Keithley, Cleveland, $\mathrm{OH}$ ) at $10-\mathrm{ms}$ intervals. Numerical analyses were performed on-line using an IBM-PC-XT 16-bit computer (IBM, Inc. Boca Raton, FL). We used an oscilloscope (model 5111a, Tektronix, Inc., Beaverton, OR) to measure the $90 \%$ response times of the flow and pressure transducer systems; they were 140 and $24 \mathrm{~ms}$.

Experimental protocol. At $4 \mathrm{~h}$ postnatal age, passive exhalation mechanics of the respiratory system were measured by using methods patterned after LeSouef et al. (10). Measurements were begun by clamping the polyvinyl chloride tubing of the fabricated clamp connector at, or near, peak inspiration. Flow was interrupted for $5 \mathrm{~s}$ to allow pressures within the lung to reach equilibrium. The clamp was released and the lambs exhaled passively through the pneumotachometer to the atmosphere. During the period of measurements, the animals gave no evidence of attempting to breathe spontaneously.

\section{RESULTS}

Table 1 lists the airway pressures used and the arterial blood gas values obtained from the lambs just before mechanics measurements. The lambs required high concentrations of oxygen and high airway pressures to maintain normal levels of oxygenation, ventilation and functional residual capacity.

All 10 lambs studied had nonlinear flow-volume curves (see the example in Fig. 2). The second half of exhalation was dominated by the portions of the lung emptying slowly. The measured results (represented by the circles in Fig. 2) were closely approximated by values calculated using the two-compartment lung model; but, they were poorly represented by the values calculated using the single compartment model.

The single compartment $\tau$ estimates were obtained by using a linear regression through flow-volume values between 30 and $90 \%$ of the exhaled volume. The points used in the regression were weighted evenly in the volume exhaled as opposed to the time of exhalation. The results of $\tau$, quasistatic $\mathrm{C}$ and calculated $\mathrm{R}$ are listed in Table 2.

The results of the two-compartment analysis show that approximately one-third of the volume exhaled came from the fast compartment (Table 3). The resistance of the slow compartment was five times greater in magnitude than the resistance of the fast compartment.

Table 1. Mechanical ventilator settings and arterial blood-gas values of the preterm lambs (mean $\pm S D)^{*}$

\begin{tabular}{rrrrrrr}
\multicolumn{1}{c}{ PIP } & PEEP & MAP & \multicolumn{1}{c}{$\mathrm{FIO}_{2}$} & $\mathrm{PaO}_{2}$ & $\mathrm{PaCO}_{2}$ & \multicolumn{1}{c}{$\mathrm{pH}$} \\
\hline 43.3 & 7.9 & 14.9 & 0.90 & 74 & 42 & 7.43 \\
\pm 14.6 & \pm 1.8 & \pm 3.8 & \pm 0.10 & \pm 56 & \pm 9 & \pm 0.07 \\
\hline
\end{tabular}

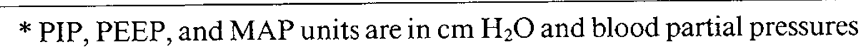
units are in $\mathrm{mm} \mathrm{Hg}$.

Table 2. Single compartment analysis of respiratory system lung mechanics (mean $\pm S D$ )

\begin{tabular}{ccc}
\hline$\tau(\mathrm{s})$ & $\mathrm{R}\left(\mathrm{cm} \mathrm{H} \mathrm{H}_{2} \mathrm{O} / \mathrm{L} / \mathrm{s}\right)$ & $\mathrm{C}\left(\mathrm{mL} / \mathrm{cm} \mathrm{H}_{2} \mathrm{O}\right)$ \\
\hline 0.16 & 92 & 1.8 \\
\pm 0.07 & \pm 17 & \pm 1.1 \\
\hline
\end{tabular}

\section{DISCUSSION}

At $4 \mathrm{~h}$ postnatal age, all of the lambs required more than $70 \%$ inspired oxygen concentrations to maintain arterial $\mathrm{PO}_{2}$ of more than $60 \mathrm{~mm} \mathrm{Hg}$. PEEP levels averaging around $8 \mathrm{~cm} \mathrm{H}_{2} \mathrm{O}$ were used to maintain the functional residual capacity in the normal range. These results coupled with the low lung compliances are consistent with the concept of the preterm lamb as a model for severe HMD (7).

We measured passive exhalation mechanics in 130 - $\mathrm{d}$ gestation preterm lambs. Our single compartment results are comparable to those reported for newborn lambs $(12,13)$; however, comparisons are complicated by the differences in methods used to obtain mechanics constants. Our quasistatic compliance of the respiratory system results $\left(0.85 \pm 0.42 \mathrm{SD} \mathrm{mL} / \mathrm{cm} \mathrm{H}_{2} \mathrm{O} / \mathrm{kg}\right)$ are similar to the dynamic lung compliance results reported for 140 d gestation lambs $\left(0.77 \pm 0.20 \mathrm{~mL} / \mathrm{cm} \mathrm{H}_{2} \mathrm{O} / \mathrm{kg}\right)(12)$; and, as expected, our results are lower than the values obtained from full term lambs $\left(1.85 \pm 0.25 \mathrm{~mL} / \mathrm{cm} \mathrm{H}_{2} \mathrm{O} / \mathrm{kg}\right)(13)$. Our resistance of the respiratory system results $\left(92 \pm 17 \mathrm{~cm} \mathrm{H} \mathrm{H}_{2} \mathrm{O} / \mathrm{L} / \mathrm{s}\right)$ were higher than the pulmonary resistance of $140-\mathrm{d}$ lambs $(70 \pm$ $30)$ and full-term lambs $(24 \pm 4)$. We would expect the resistance of the respiratory system to be greater than pulmonary resistance values where transpulmonary pressures are used. In addition to gestational age, the difference between our results and the fullterm lambs results can be partially explained by the use of anesthesia in our lambs. The full term lambs studied by Davis et al. (13) were awake and breathing spontaneously. Our lambs were well sedated and made no effort to breathe; this allowed for complete exhalation to a relaxation lung volume below the dynamic functional residual volume of the spontaneously breathing lambs.

The most striking finding in our study was the observation of a nonlinear passive exhalation flow-volume curve. Our data cannot be well explained by the use of single constants for compliance and resistance. Single valued models yield linear flow-volume curves and the figure clearly demonstrates nonlinear behavior in premature lambs. Therefore, accurate representation of the data requires more complex modeling. The benefit in applying complex models is that they may yield additional insight into mechanism causing alterations in the mechanics of the diseased lung.

Mathematical models of the lung that assume linear solutions to the equation of motion by applying linear regressions to nonlinear data are bound to produce erroneous estimates of compliance, resistance, and time constant. The flow-volume figure shows that the majority of data points sampled by the computer lie in the final $20 \%$ of exhalation. Therefore, calculations of lung mechanics using points weighted evenly in time would be greatly influenced by values obtained in the latter portion of exhalation. To avoid this complication in our estimate of average $\tau$, we weighted the flow-volume points used to calculate $\tau$ evenly in volume rather than time. To accomplish this, we divided the exhaled volume into 10 equal volumes, then used seven points between 30 and $90 \%$ of exhalation in our linear regression calculation of $\tau$. The values in the first $30 \%$ of exhalation were not used so that we could neglect the portion of exhalation where gas acceleration and transducer response time may adversely affect the calculations. The final $10 \%$ of exhalation was neglected because of noise in the flow signal due to cardiogenic effects.

Curvature in the flow-volume plots (Fig. 2) can be explained by considering that the lung time constant is a function of exhaled volume $[\tau=\tau(\mathrm{V})]$, that is, both $\mathrm{C}$ and $\mathrm{R}$ are functions of volume

Table 3. Two-compartment analysis of passive exhalation flow-volume curves (mean $\pm S D$ )

\begin{tabular}{ccccc}
\hline Compartment & $\tau(\mathrm{s})$ & $\mathrm{R}(\mathrm{cm} \mathrm{H} \mathrm{O} / \mathrm{L} / \mathrm{s})$ & $\mathrm{C}\left(\mathrm{mL} / \mathrm{cm} \mathrm{H}_{2} \mathrm{O}\right)$ & $\mathrm{fV}(\mathrm{mean} \pm \mathrm{SD})$ \\
\hline 1 & $0.10 \pm 0.04$ & $90 \pm 28$ & $1.1 \pm 0.5$ & $0.65 \pm 0.13$ \\
2 & $0.25 \pm 0.12$ & $503 \pm 288$ & $0.7 \pm 0.6$ & $0.35 \pm 0.13$ \\
\hline
\end{tabular}


$[C=C(V)$ and $R=R(V)]$. A second consideration would be that the lung is made up of two populations of lung units having different time constants (Fig. 1) (14). The results from our measurements are inconclusive as to which of the two models more accurately depicts the actual pulmonary pathophysiology of the premature lamb. However, the model of two resistancecapacitor compartments in parallel (equation 5) does represent the passive exhalation data very well. The model also provides a basis for discussing the pathophysiology of HMD which could cause uneven emptying of respiratory units during passive exhalation.

We have considered two possible physiologic explanations that are supported by the two-compartment model. The first consists of the slow compartment being made up of relatively normal terminal respiratory units whereas the fast compartment consists of surfactant deficient lung units with greatly decreased compliance and mildly increased resistance. A comparison of the compliances and resistances of the two compartments in Table 3, however, does not support this explanation. The compliances of the two compartments are relatively similar with the slow compartment approximately $40 \%$ less than the fast compartment. The slow compartment resistance is about five times more than the fast compartment resistance. We realize that these comparisons of compartments are limited because the volume of each of the compartments is unknown. Thus, specific compliances (and conductances) cannot be calculated for more accurate comparisons. We can also look at the time constant measurement results to speculate about the validity of our physiologic explanations for the two-compartment model. To support the hypothesis that the slow compartment represents the relatively healthy lung units, the time constant of slow compartment should approximate values observed in healthy lambs. Calculated estimates of the time constant (the product of resistance and compliance of the respiratory system) of full-term lambs is $0.11 \mathrm{~s} \mathrm{(13).} \mathrm{This} \mathrm{is}$ less than the slow compartment time constant of $0.25 \mathrm{~s}$ that we observed in our lambs. Because of these inconsistencies, we reject the hypothesis that the slow compartment consists of the relatively healthy portions of the lung.

The second physiologic explanation of a two-compartment model consists of the slow compartment being made up of surfactant-deficient terminal respiratory units. Insufficient surfactant can lead to alveolar and small airway instability. The surfactant-deficient alveoli would have a decreased compliance and these alveoli surrounding small airways would cause a large increase in the resistance: the result would be a long time constant. The fast compartment would consist of the relatively normal respiratory units that are probably overdistended having a reduced compliance and resistance. This hypothesis is supported by our results in Table 3 where the compliance of the slow compartment is less than the compliance of the fast compartment and the resistance of the slow compartment is much greater than the resistance of the fast compartment.

This second interpretation of the two-compartment model is consistent with the findings of Corbet et al. (1) and Hansen et al. (4) where there was evidence of a very low ventilationperfusion ratio compartment. It is also consistent with the nitrogen washout results obtained on infants with HMD (6). The latter study revealed an uneven distribution of ventilation. The "slow time constant space" was interpreted as the surfacantdeficient respiratory units which, due to alterations in compliance and resistance, would receive relatively less tidal volume per unit lung volume than the more healthy lung units. Such comparisons are difficult because the mathematical modeling used to obtain the nitrogen washout time constant is different from the lung mechanics time constant. The nitrogen washout time constant describes the exponential decay of alveolar nitrogen concentration during oxygen breathing (washout) and it is directly related to resistance and inversely related to compliance; the lung mechanics time constant equals the product of resistance and compliance and is directly related to both variables. It is important to note that the results of the two compartment analysis listed in Table 3 are consistent with the results of both the ventilation-perfusion and the distribution of ventilation studies. The model suggesting that $\mathrm{C}=\mathrm{C}(\mathrm{V})$ and $\mathrm{R}=\mathrm{R}(\mathrm{V})$ does not account for a distribution of ventilation and, therefore, is not consistent with these studies demonstrating lung inhomogeneities.

We conclude that single constant values for compliance and resistance do not accurately portray the passive exhalation lung mechanics of premature lambs with HMD. The two-compartment model, however, can be used to describe the flow-volume curves very accurately. We favor the interpretation that consists of a slow space made up of surfactant-deficient respiratory units even though this interpretation of the data is speculative and needs further study. The importance of revealing the appropriate physiologic explanation of the nonlinear flow-volume plots is apparent when you consider the widely divergent clinical implications of the different explanations. Results from an accurate model of the lung mechanics of infants with HMD could yield very useful information to clinicians when they are changing ventilator settings or when they wish to monitor the infant's severity and stage of disease.

\section{REFERENCES}

1. Corbet AJS, Ross JA, Beaudry PH, Stern L 1974 Ventilation-perfusion relationships as assessed by a- $\mathrm{AD}_{\mathrm{N} 2}$ in hyaline membrane disease. J Appl Physiol 38:74-81

2. Corbet AJS, Ross JA, Beaudry PH, Stern L 1975 Effect of positive pressure breathing on a- $\mathrm{AD}_{\mathrm{N} 2}$ in hyaline membrane disease. J Appl Physiol 38:33-38

3. Nelson NM, Prod'hom SL, Cherry RB, Lipsitz PJ, Smith CA 1963 Pulmonary function in the newborn infant: the alveolar-arterial oxygen gradient. J Appl Physiol 18:534-538

4. Hansen TN, Corbet AJS, Kenny JD, Courtney JD, Rudolph AJ 1979 Effects of oxygen and constant positive pressure breathing on $\mathrm{ADCO}_{2}$ in hyaline membrane disease. Pediatr Res 13:1167-1171

5. Landers SR, Hansen TN, Stevener MJ, Corbet AJS, Rudolph AJ 1986 Optimal constant distending airway pressure assessed by $\mathrm{aADCO}_{2}$ in hyaline membrane disease. Pediatr Res 20:884-889

6. Richardson CP, Jung AL 1978 Effects of continuous positive airway pressure on pulmonary function and blood gases of infants with respiratory distress syndrome. Pediatr Res 12:771-774

7. Stahlman M, LeQuire VS, Young WC, Merrill RE, Birmingham RT, Payne GA, Gray J 1978 Pathophysiology of the respiratory system in newborn lambs. Am J Dis Child 108:375-393

8. Perez-Fontan JJ, Heldt GP, Gregory GA 1985 Resistance and inertia of endotracheal tubes used in infants during periodic flow. Crit Care Med 13:1052-1055

9. McIlroy MB, Tierney DF, Nadel JA 1963 A new method for measurement of compliance and resistance of lungs and thorax. J Appl Physiol 18:424-427

10. LeSouef PN, England SJ, Bryan AC 1984 Passive respiratory mechanics in newborns and children. Am Rev Respir Dis 129:552-556

11. Solca M, Kolobow T, Huang HH, Chen V, Buckhold DK, Pierce JE 1964 Respiratory distress syndrome in immature lambs. Am Rev Respir Dis 129:979-984

12. Shaffer TH, Delivoria-Papadopoulos M, Arcinue E, Paez P, Dubois AB 1976 Pulmonary function in premature lambs during the first few hours of life. Respir Phys 28:179-188

13. Davis GM, Coates AL, Dalle D, Bureau MA 1988 Measurements of pulmonary mechanics in the newborn lamb: a comparison of three techniques. J Appl Physiol 64:972-981

14. Otis AB, McKerrow CB, Bartlett RA, Mead J, Mcllroy MB, Silverstone NJ, Radford EP 1956 Mechanical factors in distribution of pulmonary ventilation. Distr Pulmon Ventil 8:427-443 